\title{
Bortezomib treats renal graft rejection
}

Bortezomib could be more effective than standard therapies for antibody-mediated rejection and acute cellular rejection in renal transplant recipients, according to a pilot study led by Steve Woodle of the University of Cincinnati.

"We have not been impressed with the clinical results of currently available agents", says Woodle. "Our impression was that many patients experience severe damage and lose their kidney transplants within relatively short periods of time-months to 1-2 years-after therapy for antibodymediated rejection." Standard treatments do not directly affect plasma cells, which are the major source of antibodies.

In their search for agents with activity against plasma cells, the Woodle group selected the proteasome inhibitor bortezomib, licensed by the FDA for the treatment of multiple myeloma. This drug successfully treated eight episodes of concomitant antibody-mediated rejection and acute cellular rejection in six kidney or kidney-pancreas transplant recipients who failed to respond to standard therapies. All patients showed biopsy-confirmed resolution or improvement of rejection, with marked declines in donor-specific antibody levels. Adverse events related to bortezomib resolved satisfactorily. "We were impressed that with only a single cycle of the drug, such marked improvement could be observed", says Woodle.

Four clinical trials of bortezomib in different clinical settings are planned. "We will be moving beyond antibody-mediated rejection into more-chronic states where alloantibody is believed to play an important pathogenetic role", explains Woodle.

\section{Jim Casey}

Original article Everly, M. J. et al. Bortezomib provides effective therapy for antibody- and cell-mediated acute rejection. Transplantation 86, 1754-1761 (2008). 